\title{
LA DEMOCRACIA DESPUÉS DEL COMUNISMO
}

Norbert Lechner*

El tema que hoy nos preocupa puede ser planteado al modo de una paradoja: en el momento mismo en que desaparece la alternativa comunista, también se diluye el sentido de la democracia en la democracia liberal-representativa. ¿Existe alguna "correspondencia" entre ambos términos? Solamente constato que el fin del comunismo deja al desnudo a la democracia realmente existente. Antes, las democracias occidentales se justificaban por oposición a las democracias populares; a la legitimidad de origen se agregaba una legitimidad por ejercicio mediante el simple contraste con el régimen comunista. La vigencia de los derechos humanos y la elección libre y competitiva de las autoridades marcaban una diferencia sustantiva respecto a la dictadura de partido único. Simultáneamente empero, el comunismo representaba un desafio, aunque sólo fuese discursivo, para la democracia liberal. La obligaba a enfrentarse a las condiciones sociales de la democracia: la relación que guarda el autogobierno de una "comunidad de ciudadanos" con la existencia de ciertos "niveles mínimos" de igualdad y justicia social. No era que los regímenes comunistas resolvieran dicho problema, ni mucho menos; pero incluso en su fracaso, mantenían viva la pregunta por la relación entre las formas politicas de la democracia y las condiciones sociales de los ciudadanos.

* Facultad Latinoamericana de Ciencias Sociales, México. 
El colapso del comunismo obliga a las democracias occidentales a justificarse más por los méritos propios que por los defectos ajenos. Es la hora de una autoreflexión crítica. Ello implica retomar el desafío pendiente: ¿en qué medida el proceso democrático puede decidir sobre las estructuras socioeconómicas? Sabemos que nuestras sociedades han desarrollado una complejidad que cuestiona el antiguo primado de la política; los diversos campos de la vida social obedecen más y más a racionalidades y dinámicas específicas, difícilmente conmensurables entre sí, que impiden un control central por parte de la política. La lógica autoreferencial de los diferentes subsistemas concierne también a la política, que parece retrotraerse a ser un "subsistema" más. Surge entonces una pregunta tan banal como dramática ¿para qué sirve la democracia?

La actualidad del interrogante se desprende de la experiencia cotidiana. Día a día nuestros países enfrentan el dilema de tener que responder simultáneamente a las exigencias de la modernización capitalista y de la democratización, siendo que el "modelo" prevaleciente de modernización conlleva un conjunto de (reales o supuestos) "imperativos" que son rechazados en un proceso democrático de deliberación. Vale decir, una buena parte de las decisiones requeridas por las estrategias predominantes de modernización no encuentran apoyo popular. Se abre una brecha entre las decisiones "necesarias" (en función de la modernización) y las decisiones "legítimas" (en términos del procedimiento democrático) que plantea un problema de gobernabilidad. Con el fin de hacer compatibles ambas lógicas, se extiende por doquier la tendencia a restringir la democracia a una "democracia electoral". Por cierto, elecciones libres son un factor crucial en cualquier proceso de democratización, particularmente en México, pero cabe preguntarse acerca del alcance de las elecciones. La tendencia actual consiste en reducir la democracia al acto electoral y la consiguiente competencia por los partidos, sin que ello influya en el posterior proceso de toma de decisiones. Las decisiones quedan concentradas en mano de un Poder Ejecutivo fuerte, que impone la racionalidad de la modernización en tanto que el juego democrático se limita a la movilización cíclica de la adhe- 
sión popular. Estamos pues ante un tipo específico de democratización, subordinada a las exigencias de la estrategia económica: por un lado, el fortalecimiento del Poder Ejecutivo, capaz de imponer los "imperativos" de la modernización y, por el otro, una legitimación genérica del proceso mediante elecciones regulares.

No faltan buenas razones para tal división del trabajo; las dificultades de anticipar las posibles coyunturas inhiben cualquier predeterminación de resultados de las decisiones futuras. No queda sino depositar confianza en los gobernantes y ese examen de credibilidad son las elecciones. Mas el motivo principal es otro: armonizar el desarrollo de una economía capitalista de mercado con la existencia de instituciones y procedimientos democráticos. El arreglo asegura una toma de decisiones racional, acorde a las exigencias de la modernización a la vez que un respeto de las "reglas de juego" según los principios de la democracia liberal. Sin embargo, la armonización pretendida resulta ficticia por cuanto ignora un punto decisivo: la creación y reproducción del sentido del orden social.

Por extrañas razones (que no es el caso analizar aquí) todo ser humano pretende dar sentido a sus acciones, a su vida, a su mundo y no existe sociedad sin esta referencia a un sentido exteriorizado por intermedio del cual se reconoce a sí misma en tanto sociedad. Es decir, toda sociedad requiere un tipo de autorepresentación mediante la cual se hace inteligible en tanto orden colectivo. En la sociedad moderna (que ya no puede recurrir a un sentido prefijado) la producción del sentido del orden se apoya de manera importante en el proceso democrático. Podemos entender por democracia precisamente esa determinación colectiva y conflictiva del sentido del orden por medio del cual los individuos se sienten partícipes de la polis, o sea de una comunidad de ciudadanos.

El sentido de un orden no está fijado de una vez para siempre (el autoritarismo es el intento vano de imponer un sentido fijo y unívoco). Por lo mismo, también el sentido de la democracia -la constitución de una comunidad de ciudadanos- está sometido a un continuo proceso de crítica y reformulación. Precisamente el fin del comunismo permite 


\section{NORBERT LECHNER}

redescubrir la democracia como un proceso abierto. En la medida en que las trincheras de la guerra fría se borran y pierden rigidez las ideologías autojustificatorias, la democracia vuelve a aparecer como lo que siempre fue: un movimiento histórico cuyo sentido ha de ser actualizado continuamente. Los mismos procesos de transición y consolidación democrática en América Latina ya no pueden apuntar a la democracia como un punto de llegada. Hablamos de procesos de democratización para enfatizar el carácter abierto, no predeterminado que tiene la construcción de un orden democrático. Ello implica renunciar a una noción de "modelo" o "ideal" de democracia que ofrezca una medida dada con la cual juzgar los avances logrados. Hoy en día nuestra evaluación no se guía tanto por los principios definitorios del régimen democrático como por las constelaciones de los factores/actores, el ritmo y las secuencias del proceso. En esta visión procesual de la democracia adquiere una relevancia sobresaliente la dimensión temporal. Todo proceso ocurre en el tiempo. La democratización se despliega en el tiempo, mas su temporalidad no es neutra. Como toda acción política moderna, la democracia está volcada al futuro. Ahora bien, uno de los problemas que levanta el derrumbe de la revolución

228 comunista es la perspectiva de futuro.

Cuando Bobbio señala las promesas incumplidas de la democracia no se limita a contrastar la realidad democrática con el ideal democrático para constatar que la democracia realmente existente es diferente a lo que prometían los principios democráticos. Aun constatando tal brecha, ella puede no ser relevante en la medida en que una tradición establecida hace aparecer las ventajas y debilidades del régimen democrático como algo normal y natural. Donde la democracia cuenta con una larga y sólida tradición, el tiempo transcurrido ha permitido ajustar objetivos y medios, sea renunciando a las "uvas verdes", sea idealizando a la polis como una utopía imposible. En América Latina, en cambio, donde la tradición democrática es débil, la democratización significa un acto fundacional: la instauración de un nuevo orden. Incluso en aquellos países que tuvieron una historia democrática más larga (Chile, Uruguay), la interrupción traumática del proceso impide 
una simple restauración. En América Latina la instauración de la democracia se justifica por la negación del pasado ("no más autoritarismo") y mediante la promesa de un orden nuevo. Aquí enfrentamos una de las paradojas de la democracia: su fundación no puede recurrir a fundamentos previos y, por lo tanto, ha de legitimarse en nombre de su realización futura. La transición democrática anticipa el futuro. Este punto me parece crucial: las promesas de la democracia implican una promesa de futuro. Aún más: la anticipación del futuro es a la vez una promesa de un futuro mejor. La promesa de la democracia anticipa no sólo la realización de determinado hecho -la puesta en marcha de una forma concreta de procedimientos e instituciones- sino una organización mejor de la vida social. Contiene un elan emancipatorio que, usando una expresión de Marx, remite a "una libre asociación de hombres libres". Esa invocación de un mañana mejor constituye la fuerza de la promesa democrática, al menos como acto fundacional.

Sin embargo, el impulso democrático por una vida mejor choca con la experiencia actual. Ésta tiene a la vista el fracaso con que se saldaron las dos grandes variantes del esfuerzo por mejorar el mundo: el progreso técnico y el cambio revolucionario. Si el comunismo (en la fórmula leninista) surgió de la conjunción de ambas visiones, su desplome es el testimonio más notorio de su fracaso. Un fracaso tan traumático que parece arrastrar consigo la noción misma de futuro. Uno de los rasgos sobresalientes de nuestra época consiste en el desvanecimiento del futuro. Hoy por hoy, la aceleración del tiempo en un "presente omnipresente" parece devorar toda noción de mañana y, en particular, de un mañana mejor. El fenómeno tiene efectos de gran alcance: puesto que buena parte del presente se legitimaba en nombre del futuro, el desvanecimiento de éste socava un mecanismo básico de otorgar sentido. La erosión del horizonte de futuro trastoca el horizonte de sentido. Ello conmueve los cimientos del orden social. Cuando la idea de progreso histórico se disuelve ante las evidencias empíricas, la sociedad moderna pierde una de sus representaciones imaginarias fundamentales por intermedio de las cuales se reconocía a sí misma en tanto sociedad. La autorepresentación de la sociedad como orden co- 


\section{NORBERT LECHNER}

lectivo se viene abajo en el momento mismo en que una creciente fragmentación de la vida social intensifica la demanda de comunidad. Pero si la sociedad carece de noción de sí misma, los individuos pierden el sentimiento de pertenencia. Vale decir, la construcción democrática no puede apoyarse en una imagen fuerte de sociedad (independientemente de la debilidad secular de la sociedad civil), sino que debe generar desde el mismo proceso político la prometida "comunidad de ciudadanos".

En resumidas cuentas, América Latina inicia procesos de democratización con las consiguientes promesas de un futuro mejor en una época caracterizada por la erosión de los horizontes de futuro y de sentido. El desarrollo de instituciones democráticas requiere tiempo y éste es aquí y ahora un recurso escaso. La democracia nace pues en tiempos difíciles. No porque hayan desaparecido las amenazas externas y se extienda también por nuestra región la "ola democratizadora", son éstos "tiempos de democracia". Por el contrario, aquí donde la falta de tradición otorga a las promesas un lugar prioritario, las jóvenes democracias crecen en un aire enrarecido. Nadie apuesta al futuro, salvo las promesas de la democracia. 